\title{
Substituição do Milho pela Farinha de Mandioca de Varredura em Dietas de Cabras em Lactação: Produção e Composição do Leite e Digestibilidade dos Nutrientes ${ }^{1}$
}

\author{
Gisele Fernanda Mouro ${ }^{4}$, Antonio Ferriani Branco ${ }^{2,6}$, Francisco Assis Fonseca de Macedo ${ }^{3,6}$, \\ Luiz Paulo Rigolon ${ }^{3}$, Fábio José Maia ${ }^{5}$, Kátia Cylene Guimarães ${ }^{4}$, Júlio Cesar Damasceno ${ }^{3,6}$, \\ Geraldo Tadeu dos Santos ${ }^{3,6}$
}

\begin{abstract}
RESUMO - O objetivo deste trabalho foi avaliar o efeito da substituição do milho pela farinha de mandioca de varredura, em dietas de cabras Saanen em lactação, sobre o desempenho, a composição do leite (sólidos totais e proteína bruta), a digestibilidade da matéria seca (MS), matéria orgânica (MO), proteína bruta (PB), extrato etéreo (EE), fibra insolúvel em detergente neutro (FDN), e amido e a concentração dos nutrientes digestíveis totais (NDT) das dietas. Foram utilizadas quatro cabras há 100 dias em lactação. O delineamento utilizado foi o quadrado latino 4 x 4, em que os tratamentos consistiram em níveis de $0,33,67$ e $100 \%$ de substituição do milho pela farinha de varredura. Os tratamentos não influenciaram a ingestão, excreção fecal, digestão total e a digestibilidade total da MS, MO, PB, FDN e carboidratos não-fibrosos (CNF). Houve diminuição linear na excreção fecal e aumento na digestibilidade do amido, com a inclusão da farinha de mandioca de varredura. O NDT não diferiu entre as dietas estudadas, com média de 71,59\%. Houve correlação positiva entre a digestibilidade da matéria orgânica (DIGMO) e o NDT $(r=0,9472)$, permitindo estimativas do NDT a partir da equação NDT $(\%)=0,8897$ DIGMO $(\%)+10,9940\left(\mathrm{R}^{2}=0,8972\right)$. A substituição da farinha da mandioca de varredura não alterou a produção, bem como a composição do leite. Recomenda-se a utilização da farinha de mandioca de varredura em dietas de cabras em lactação, em total substituição ao milho, sem prejuízos na digestibilidade dos nutrientes e na produção.
\end{abstract}

Palavras-chave: cabras leiteiras, mandioca, NDT, produção de leite, subproduto

\section{Corn Replacement by Cassava by-Product Meal in the Lactating Goat Diets: Effects on Milk Production and Composition and Nutrients Digestibility}

\begin{abstract}
The objectives of this work were to evaluate effects of replacing corn by cassava by-product meal, in diets of Saanen lactating goats, on milk production and composition (total solids and crude protein), nutrient apparent digestibility and total digestible nutrients (TDN) of diets. Four multiparous goats fitted with ruminal cannula, with 100 days of lactation, were used. The design was a 4 x 4 Latin square and treatments as following: 0,33, 67 and 100\% replacement of corn by cassava by-product meal. Treatments did not affect intake, fecal flow and dry matter (DM), organic matter (OM), crude protein (CP), neutral fiber detergent (NDF) and non-fiber carbohydrate (NFC) total digestion (AD) and total digestibility (DIG). There was a linear fecal flow decrease and a starch digestibility increase with cassava by-product meal inclusion. TDN did not differ among diets with an average of $71.59 \%$. There was a positive correlation $(\mathrm{r}=0.9472)$ between OMDIG and TDN, making possible TDN estimation from the equation: TDN $(\%)=0.8897 \mathrm{OMDIG}$ $(\%)+10.9940\left(\mathrm{R}^{2}=0.8972\right)$. Cassava by-product inclusion did not affect milk production and composition (total solids and crude protein). These results permit to recommend inclusion of cassava by-product in goat lactating diets, in total replacement of corn without problems related to nutrient digestibility and milk production.
\end{abstract}

Key Words: by-products, cassava, dairy goats, milk prodution, TDN

\section{Introdução}

Os carboidratos são a principal fonte energética para o desenvolvimento dos microrganismos do rúmen e a taxa de produção microbiana pode ser modificada sensivelmente, quando diferentes fontes são utilizadas.
As principais diferenças estão na taxa e extensão da digestão do amido no rúmen, as quais são determinadas por inter-relações de diversos fatores, incluindo a fonte dietética de amido, as composições dietéticas, a quantidade de alimentos consumida por unidade de tempo, interações mecânicas (processamento dos

\footnotetext{
1 Parte da tese da primeira autora apresentada à Universidade Estadual de Maringá para a obtenção do título de "Mestre em Zootecnia".

2 Professor do Departamento de Zootecnia - UEM Av. Colombo, 5790. CEP 87020-900. Maringá-PR. E.mail: afbranco@uem.br

${ }^{3}$ Professor do Departamento de Zootecnia - UEM Av. Colombo, 5790. CEP 87020-900. Maringá-PR.

${ }^{4}$ Estudante de Pós-Graduação em Zootecnia - UEM Av. Colombo, 5790. CEP 87020-900. Maringá-PR. E.mail: gfmouro@hotmail.com; cylene25@hotmail.com, respectivamente.

5 Estudante de Graduação em Zootecnia - Bolsista PIBIC - UEM - Av. Colombo, 5790. CEP 87020-900. Maringá-PR. E.mail: maiafj@hotmail.com

${ }^{6}$ Pesquisador do CNPq.
} 
grãos, mastigação), interações químicas (grau de hidratação, gelatinização) e adaptação dos microrganismos ruminais (Huntington, 1997).

Embora alguns autores tenham encontrado diferentes produções de leite entre animais alimentados com diferentes taxas de degradação ruminal do amido (McCarthy et al., 1989; Weiss et al., 1989; Casper et al., 1999; Schimidely et al., 1999), outros estudos de desempenho com animais em lactação não evidenciam, claramente, que alimentos com baixas taxas de degradação ruminal do amido aumentem a produção de leite (DePeters \& Taylor, 1985; Nocek \& Tamminga, 1991; Khorasani et al., 1994). Parece ser mais claro que a glicose absorvida no intestino delgado é utilizada com maior eficiência pelo metabolismo do ruminante para a produção de leite do que os ácidos graxos voláteis (AGVs) gerados na fermentação ruminal (Nocek \& Tamminga, 1991).

A ingestão diária de MS (Caldas-Neto, 1999; Schimidely et al., 1999), MO (Rode \& Satter, 1998; Philippeau et al., 1999), PB (Khorasani et al., 1994; Caldas-Neto, 1999), FDN e fibra em detergente ácido (FDA) (McCarthy et al., 1989) para animais ruminantes, não diferiu $(\mathrm{P}>0,05)$ entre dietas com fontes de amido de rápida ou de lenta taxa de degradação ruminal, embora McCarthy et al. (1989) tenham verificado menor ingestão de MS, MO e PB e Khorasani et al. (1994) menor ingestão de MS para dietas com fontes de amido de rápida degradação ruminal.

O consumo de dietas contendo fontes de amido com altas taxas de degradação ruminal pode proporcionar maior digestibilidade aparente total da MS em vacas em lactação (McCarthy et al., 1989; Phillippeau et al., 1999). Overton et al. (1995), trabalhando com diferentes proporções de amido oriundo do milho e da cevada para vacas em lactação, verificaram que a digestão da $\mathrm{MO}$ e do amido aumentou na proporção em que o amido, oriundo de uma fonte de rápida degradação ruminal, a cevada, aumentou na dieta. No entanto, nem sempre este efeito é observado (Weiss et al., 1989).

Caldas Neto (2000) avaliou a digestibilidade aparente total de rações compostas por várias fontes de amido, alguns subprodutos da industrialização da mandioca, em novilhos Holandeses. O autor verificou que a digestibilidade aparente total da MS, MO, PB, FDN e energia não diferiu entre o milho e a farinha de mandioca de varredura, embora a do amido tenha sido maior para a farinha de varredura em relação ao milho, com médias de 90,8 e $85,0 \%$, respectivamente.

O objetivo deste trabalho foi avaliar a substituição do milho pela farinha de mandioca de varredura, em dietas de cabras Saanen em lactação, sobre o desempenho, a composição do leite (sólidos totais e proteína bruta), a digestibilidade total da MS, MO, PB, EE, FDN e amido e a concentração dos nutrientes digestíveis totais (NDT) das dietas.

\section{Material e Métodos}

Este experimento foi realizado no setor de Nutrição de Ruminantes da Fazenda Experimental de Iguatemi, campus da Universidade Estadual de Maringá, localizada no distrito de Iguatemi, e no Laboratório de Análises de Alimentos e Nutrição Animal -UEM, no período de outubro a dezembro de 2000.

Foram utilizadas quatro cabras da raça Saanen, canuladas no rúmen e pesando, em média $50 \mathrm{~kg}$. As cabras estavam há 100 dias em lactação, com produção média de $2 \mathrm{~kg}$ de leite/dia e foram alojadas em gaiolas de metal com piso ripado de madeira, com bebedouro e comedouro individuais.

Os animais foram alimentados duas vezes ao dia, às 8 e $16 \mathrm{~h}$ e receberam água limpa à vontade. Além disso, foi mantido um controle higiênico e sanitário rigoroso dos animais, sendo as gaiolas e animais higienizados duas vezes por dia. As cabras foram ordenhadas duas vezes por dia, às $8 \mathrm{~h} 30$ e $15 \mathrm{~h}$.

Os animais receberam dieta balanceada, de forma a atender às exigências de mantença e lactação, segundo o AFRC (1993), com uma relação volumoso:concentrado de 40:60, sendo o volumoso, o feno de alfafa. O delineamento experimental utilizado foi quadrado latino 4 x 4 . A composição das rações experimentais, formuladas a partir de dados das tabelas do NRC (1996), encontra-se na Tabela 1. Os tratamentos consistiram na substituição no concentrado, do milho pela farinha de mandioca de varredura, sendo as dietas:

$\mathrm{T}_{0}$ = volumoso + ração com $0 \%$ de substituição; $\mathrm{T}_{33}=$ volumoso + ração com $33 \%$ de substituição; $\mathrm{T}_{67}=$ volumoso + ração com $67 \%$ de substituição; $\mathrm{T}_{100}=$ volumoso + ração com $100 \%$ de substituição. Os períodos experimentais tiveram duração de 14 dias. A pesagem do leite foi realizada diariamente, mas somente os dados do período, compreendendo entre o $8^{\circ}$ e $14^{\circ}$, foi utilizado para avaliação das 
Tabela 1 - Composição percentual e química das dietas experimentais (\% na MS)

Table 1 - Percentual and chemical composition of experimental diets (\% dry matter)

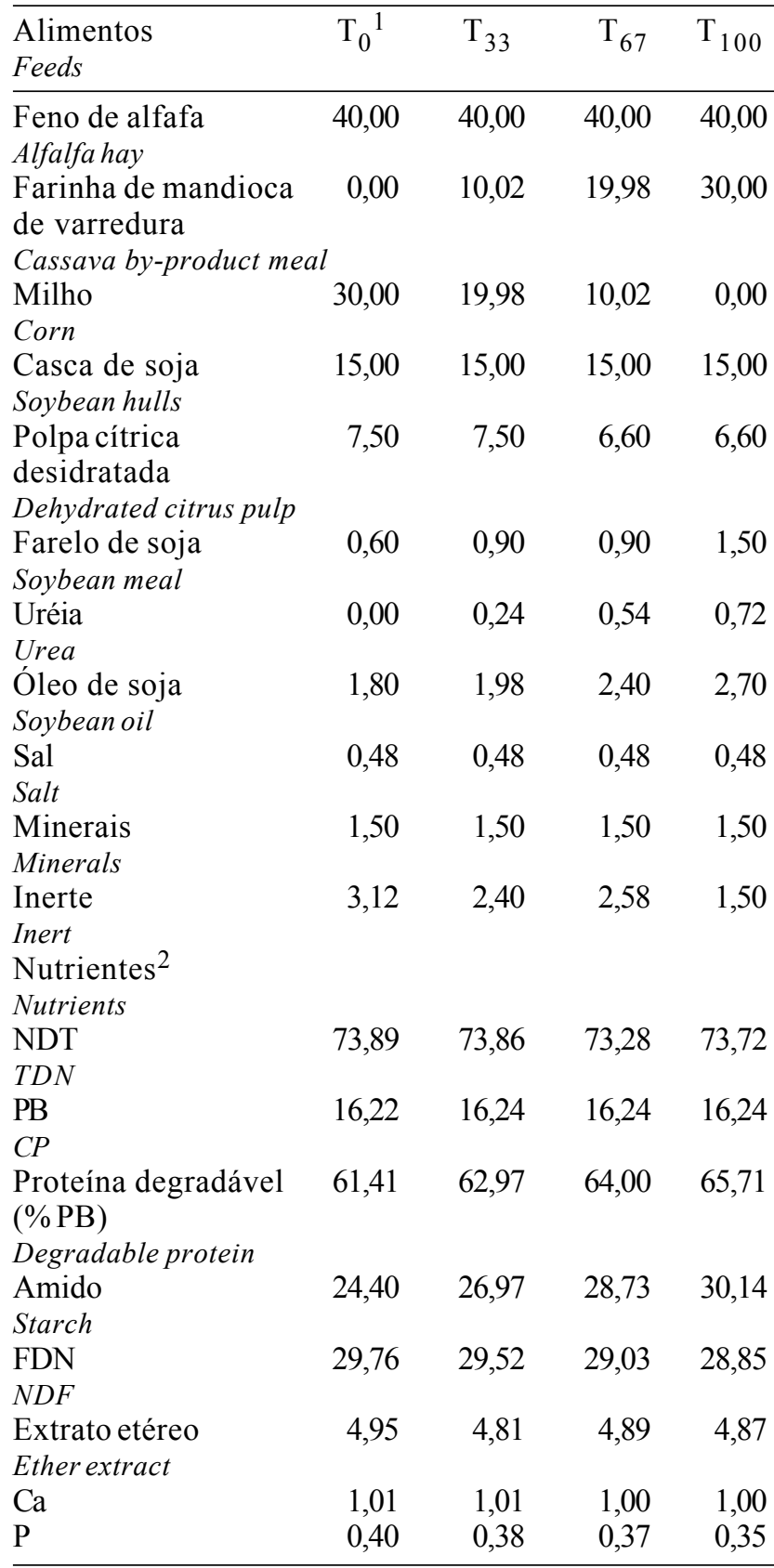

${ }^{1} \mathrm{~T}_{0}$ : dieta com $0 \%$ de substituição do milho pela farinha de varredura; $\mathrm{T}_{33}$ : dieta com $33 \%$ de substituição; $\mathrm{T}_{67}$ : dieta com $67 \%$ de substituição; $T_{100}$ : dieta com $100 \%$ de substituição.

$T_{0}$ : diet with $0 \%$ replacement corn by cassava by-product meal; $T_{33}$ : diet with $33 \%$ replacement; $T_{67}$ : diet with $67 \%$ replacement; $T_{100}$ : diet with $100 \%$ replacement.

dietas. As amostras de leite foram colhidas durante três dias em cada período experimental, $11^{\circ}$ ao $13^{\circ}$ dias, duas vezes por dia, em horários regulares, $8 \mathrm{~h} 30$ e $15 \mathrm{~h}$, preservadas com 2-bromo-2-nitropropano1,3 diol (Bronopol) e refrigeradas a $4^{\circ} \mathrm{C}$. As amostras da manhã e tarde foram compostas proporcionalmente por dia. Nas amostras compostas do leite foram determinados os teores de extrato seco e nitrogênio total, pelo procedimento de Kjeldahl (Barbano et al., 1990).

As amostras de alimentos e rações foram colhidas a cada 15 dias, no momento da mistura das mesmas. As rações foram analisadas por período e as amostras de alimentos foram compostas, sendo uma de cada, para todo o experimento. As sobras foram pesadas e amostradas todos os dias e, posteriormente, compostas por animal e período.

As amostras fecais $(25 \mathrm{~g})$ foram colhidas do $9^{\circ}$ ao $13^{\circ}$ dia do período experimental, duas vezes ao dia, no $9^{\circ}$ dia as 8 e $13 \mathrm{~h}$, havendo incremento de uma hora, das colheitas de um dia para o outro, perfazendo um total de dez amostragens. Ainda, no momento da colheita, foram compostas por tratamento/animal/ período e, posteriormente, secas em estufa de circulação forçada de ar, a $55^{\circ} \mathrm{C}$ por 72 horas.

Os alimentos, rações, sobras e fezes foram analisados quanto aos teores MS, MO, PB e EE, de acordo com as metodologias descritas por Silva (1990). As determinações de FDN foram realizadas segundo Van Soest et al. (1991). O teor de amido das amostras foi analisado pelo método de Poore et al. (1989) adaptado por Pereira \& Rossi Jr. (1995).

O indicador externo utilizado foi o óxido de cromo, ministrado via intra-ruminal, fornecido nos horários de alimentação, perfazendo um total de $5 \mathrm{~g} / \mathrm{animal} /$ dia. O teor de cromo nas amostras de fezes foi determinado por espectofotometria de absorção atômica, conforme Willians et al. (1962). A partir da utilização do indicador, determinaram-se os coeficientes de digestibilidade total da MS, MO, PB, EE, FDN, CNF e amido.

A porcentagem de NDT foi determinada pela equação descrita por Weiss (1999):

$$
\mathrm{NDT}=\mathrm{PBD}+\mathrm{FDND}+\mathrm{CNFD}+(\text { EEDx } 2,25)
$$

em que: $\mathrm{NDT}=$ nutrientes digestíveis totais; $\mathrm{PBD}=$ proteína bruta digestível; FDND = fibra em detergente neutro digestível; CNFD = carboidratos não fibrosos digestíveis; $\mathrm{EED}=$ extrato etéreo digestível.

sendo: $\mathrm{CNF}=100-(\mathrm{PB}+\mathrm{FDN}+\mathrm{EE}+\mathrm{MM})$ em que: $\mathrm{CNF}=$ carboidratos não-fibrosos; $\mathrm{MM}=$ matéria mineral; demais abreviações já citadas anteriormente.

Os dados foram analisados por intermédio do programa SAEG, utilizando-se seguinte modelo matemático:

$$
\mathrm{Y}_{\mathrm{ijk}}=\mathrm{m}+\mathrm{T}_{\mathrm{i}}+\mathrm{A}_{\mathrm{j}}+\mathrm{P}_{\mathrm{k}}+\mathrm{e}_{\mathrm{ijk}}
$$

em que: $\mathrm{m}=$ constante geral; $\mathrm{T}_{\mathrm{i}}=$ efeito do tratamento $i$, variando de 1 a $4 ; \mathrm{A}_{\mathrm{j}}=$ efeito do animal $j$, variando 
de 1 a 4; $\mathrm{P}_{\mathrm{k}}=$ efeito do período $k$, variando de 1 a 4 ; $\mathrm{e}_{\mathrm{ijk}}=$ erro aleatório associado a cada observação ijk.

Foi ainda estimada a correlação entre os dados de digestibilidade aparente da matéria orgânica e nutrientes digestíveis totais, utilizando-se o método de Pearson, utilizando-se o programa SAEG (Universidade Federal de Viçosa - UFV, 1983), a 5\% de significância.

\section{Resultados e Discussão}

Os resultados referentes à ingestão, excreção fecal, digestão total e digestibilidade total da matéria seca, matéria orgânica e amido são mostrados na Tabela 2.

Para ingestão de matéria seca, matéria orgânica e amido não houve diferença $(\mathrm{P}>0,05)$, entre os níveis de substituição estudados, ficando a ingestão de MS em média de 3,5\%, em relação do peso vivo (PV). O fornecimento de MS foi limitado em 4\% do PV e, dessa forma, esses resultados podem ser considerados coerentes. Embora o fornecimento de MS tenha sido limitado a $4 \%$ do PV, a hipótese de diferenças no consumo foi considerada, porque os animais apresentaram comportamento individual na ingestão, com a ocorrência de sobras.

Embora a ingestão de MS não tenha sido influenciada pela substituição do milho pela farinha de mandioca de varredura no presente experimento, a utilização de fontes de amido de alta degradabilidade ruminal em dietas contendo alto nível de amido, no caso do presente experimento 25 a $30 \%$ do total da MS ingerida, pode diminuir a ingestão de MS (Owens et al., 1998).

Os resultados obtidos neste trabalho com relação à ingestão de $\mathrm{MS}$, confirmam os obtidos por Casper et al. (1999) e Schimidely et al. (1999), que não observaram diferença $(\mathrm{P}>0,05)$ na ingestão de $\mathrm{MS}$, de dietas contendo diferentes fontes de amido. No entanto, McCarthy et al. (1989) observaram menor ingestão de MS em animais que consumiram carboidratos de rápida degradação ruminal, resultados que foram confirmados por Khorasani et al. (1994), os quais verificaram que uma dieta com rápida degradação ruminal do amido e da proteína proporcionou menor ingestão de MS.

Marques (1999) e Jorge et al. (2000) verificaram menor consumo de MS para novilhas e bezerros Holandeses, respectivamente, alimentados com rações contendo farinha de mandioca de varredura, em relação aos alimentados com rações contendo milho e atribuíram o menor consumo à textura da farinha que apresentou muito pó em sua constituição. Zeoula et al. (2000) não observaram diminuição do consumo de MS por ovinos alimentados com níveis de 25 a $100 \%$ de substituição do milho pela farinha de mandioca de varredura, em dietas com cerca de $38 \%$ destes alimentos.

Excreção fecal da MS e MO não foi influenciada $(\mathrm{P}>0,05)$ pela substituição do milho pela farinha de mandioca de varredura, no entanto, a excreção do amido apresentou comportamento linear negativo $(\mathrm{P}<0,05)$, ou seja, com o aumento da inclusão da farinha nas dietas houve menor excreção fecal deste componente. Não houve efeito $(\mathrm{P}>0,05)$ da substituição do milho pela farinha de mandioca de varredura na digestão aparente da MS, MO e amido.

Não houve diferença $(\mathrm{P}>0,05)$ na digestibilidade total da MS e da MO, em função da substituição do milho pela farinha de mandioca de varredura, confirmando os resultados obtidos por Caldas Neto (1999) e Zeoula et al. (2000), que trabalharam com as mesmas fontes. A digestibilidade do amido apresentou efeito linear, ou seja, o aumento da proporção de farinha de mandioca de varredura aumentou a digestibilidade do amido. Estes resultados são semelhantes aos publicados pela vasta revisão de Nocek \& Tamminga (1991) que verificaram ser a digestibilidade do amido influenciada na maior parte pela digestibilidade ruminal, do que pela pós ruminal. A maior digestibilidade ruminal do amido para a casca de mandioca, quando comparada ao milho, pode ser compensada pela maior digestão intestinal apresentada pelo milho, resultando em uma digestibilidade semelhante entre as fontes, verificado por Fregadolli (2000), ao estudar o efeito da sincronização das taxas de degradação da energia e da proteína. O autor não encontrou diferença $(P>0,05)$ entre rações com diferentes fontes de energia e nitrogênio sobre a digestibilidade aparente da MS, MO e amido.

A digestibilidade do amido aumenta na proporção em que o amido, oriundo de uma fonte de rápida degradação ruminal eleva-se na dieta (Overton et al., 1995). Estes resultados também foram confirmados por Phillippeau et al. (1999), que estudaram a influência da fonte de grãos sobre a extensão da digestão em novilhos e observaram maior digestibilidade aparente total do amido com trigo (95,9\%) que com milho (82,9\%).

Os resultados sobre a ingestão, excreção fecal, digestão total e digestibilidade total para a PB, FDN, CNF eEE, bem como o NDT das dietas, expressos em gramas ou 
Tabela 2 - Médias, equações de regressão e coeficientes de determinação $\left(R^{2}\right)$ para ingestão (ING), excreção fecal (EF), digestão total (DT), digestibilidade total (DIG) da matéria seca, matéria orgânica e do amido

Table 2 - Averages, regression equations and coefficients determination $\left(R^{2}\right)$ for intake (INT), feces flow (FF), total digestion (TD), total digestibility (DIG) of dry matter, organic matter and starch

\begin{tabular}{|c|c|c|c|c|c|c|c|}
\hline & \multicolumn{4}{|c|}{$\begin{array}{c}\text { Tratamentos } \\
\text { Treatments }\end{array}$} & \multirow[t]{2}{*}{$\begin{array}{l}\text { Regressão } \\
\text { Regression }\end{array}$} & \multirow[t]{2}{*}{$\mathrm{R}^{2}$} & \multirow[t]{2}{*}{$\mathrm{CV}(\%)$} \\
\hline & $\mathrm{T}_{0}^{1}$ & $\mathrm{~T}_{33}$ & $\mathrm{~T}_{67}$ & $\mathrm{~T}_{100}$ & & & \\
\hline \multicolumn{8}{|c|}{$\begin{array}{l}\text { Matéria seca } \\
\text { Dry matter }\end{array}$} \\
\hline $\begin{array}{l}\mathrm{ING}(\mathrm{g} / \mathrm{dia}) \\
I N T\end{array}$ & 1892,77 & 1742,17 & 1733,88 & 1891,87 & $Y=1815,17$ & NS & 11,67 \\
\hline $\begin{array}{l}\mathrm{EF}(\mathrm{g} / \mathrm{dia}) \\
F F\end{array}$ & 585,67 & 507,83 & 541,64 & 556,03 & $\mathrm{Y}=547,79$ & NS & 22,43 \\
\hline $\begin{array}{l}\mathrm{DT}(\mathrm{g} / \mathrm{dia}) \\
T D\end{array}$ & 1307,10 & 1234,34 & 1192,24 & 1335,84 & $Y=1267,38$ & NS & 10,56 \\
\hline $\begin{array}{l}\mathrm{DIG}(\%) \\
D I G\end{array}$ & 69,00 & 70,12 & 68,86 & 70,36 & $\mathrm{Y}=69,59$ & NS & 5,98 \\
\hline \multicolumn{8}{|c|}{$\begin{array}{l}\text { Matéria orgânica } \\
\text { Organic matter }\end{array}$} \\
\hline $\begin{array}{l}\mathrm{ING}(\mathrm{g} / \mathrm{dia}) \\
I N T\end{array}$ & 1707,01 & 1593,05 & 1587,01 & 1729,52 & $Y=1654,15$ & NS & 11,25 \\
\hline $\begin{array}{l}\mathrm{EF}(\mathrm{g} / \mathrm{dia}) \\
F F\end{array}$ & 434,02 & 367,54 & 423,32 & 415,40 & $Y=410,07$ & NS & 24,56 \\
\hline $\begin{array}{l}\mathrm{DT}(\mathrm{g} / \mathrm{dia}) \\
T D\end{array}$ & 1272,99 & 1225,51 & 1163,69 & 1314,12 & $Y=1244,08$ & NS & 10,38 \\
\hline $\begin{array}{l}\mathrm{DIG}(\%) \\
D I G\end{array}$ & 74,51 & 76,10 & 73,47 & 75,73 & $\mathrm{Y}=74,95$ & NS & 5,21 \\
\hline \multicolumn{8}{|c|}{$\begin{array}{l}\text { Amido } \\
\text { Starch }\end{array}$} \\
\hline $\begin{array}{l}\mathrm{ING}(\mathrm{g} / \mathrm{dia}) \\
I N T\end{array}$ & 466,26 & 455,57 & 515,44 & 555,14 & $\mathrm{Y}=498,10$ & NS & 17,87 \\
\hline $\begin{array}{l}\mathrm{EF}(\mathrm{g} / \mathrm{dia}) \\
F F\end{array}$ & 23,20 & 18,57 & 8,65 & 10,57 & $\mathrm{Y}=15,25-4,78 \mathrm{x}$ & 0,82 & 44,05 \\
\hline $\begin{array}{l}\text { DT (g/dia) } \\
T D\end{array}$ & 443,06 & 437,00 & 506,79 & 544,57 & $\mathrm{Y}=482,86$ & NS & 18,55 \\
\hline $\begin{array}{l}\mathrm{DIG}(\%) \\
D I G\end{array}$ & 94,83 & 96,05 & 98,29 & 98,08 & $Y=96,82+1,20 x$ & 0,86 & 1,69 \\
\hline
\end{tabular}

${ }^{1} \mathrm{~T}_{0}$ : dieta com $0 \%$ de substituição do milho pela farinha de varredura; $\mathrm{T}_{33}$ : dieta com $33 \%$ de substituição; $\mathrm{T}_{67}$ : dieta com $67 \%$ de substituição; $\mathrm{T}_{100}$ : dieta com $100 \%$ de substituição.

$T_{0}$ : diet with $0 \%$ replacement corn by cassava by-product meal; $T_{33}$ : diet with $33 \%$ replacement; $T_{67}$ : diet with $67 \%$ replacement; $T_{100}$ : diet with $100 \%$ replacement.

como porcentagem da MS, encontram-se na Tabela 3.

Não houve efeito $(\mathrm{P}>0,05)$ da substituição do milho pela farinha de mandioca de varredura sobre a ingestão, excreção fecal, digestão total e digestibilidade total da proteína, FDN e CNF. Com relação ao extrato etéreo, houve diminuição linear $(\mathrm{P}>0,05)$ da ingestão, digestão total e da digestibilidade com a inclusão da farinha de mandioca de varredura nas dietas. A excreção fecal de extrato etéreo não foi influenciada pelos tratamentos.

$\mathrm{O}$ efeito de diferentes fontes de amido sobre a digestibilidade aparente total da proteína não foi observado por Rode \& Satter (1988). Caldas Neto (1999) também não encontrou diferenças na digestibilidade da PB e da FDN entre dietas, contendo o milho ou a farinha de mandioca de varredura como fonte de amido. Diferentemente, Fregadolli (2000) encontrou menor digestibilidade de FDN em dietas com altas taxas de degradação ruminal do amido e da proteína.

McCarthy et al. (1989) encontraram menor digestibilidade de FDN em dietas que tinham como base fontes com altas taxas de degradação ruminal do amido. Overton et al. (1995) atribuem a diminuição da digestibilidade de FDN, à medida que aumenta a proporção dietética de fontes com alta taxa de degradação ruminal do amido, à diminuição linear dos 
Tabela 3 - Médias, equações de regressão e coeficientes de determinação $\left(R^{2}\right)$ para ingestão (ING), excreção fecal (EF), digestão total (DT), digestibilidade total (DIG) da proteína bruta, fibra em detergente neuto, carboidratos não-estruturais, extrato etéreo e nutrientes digestíveis totais

Table 3 - Averages, regression equations and determination coefficients ( $R^{2}$ ) for intake (INT), feces flow (FF), total digestion (TD), total digestibility (DIG) of crude protein, neutral detergent fiber, nonfiber carbohydrates, ether extract and total digestible nutrients

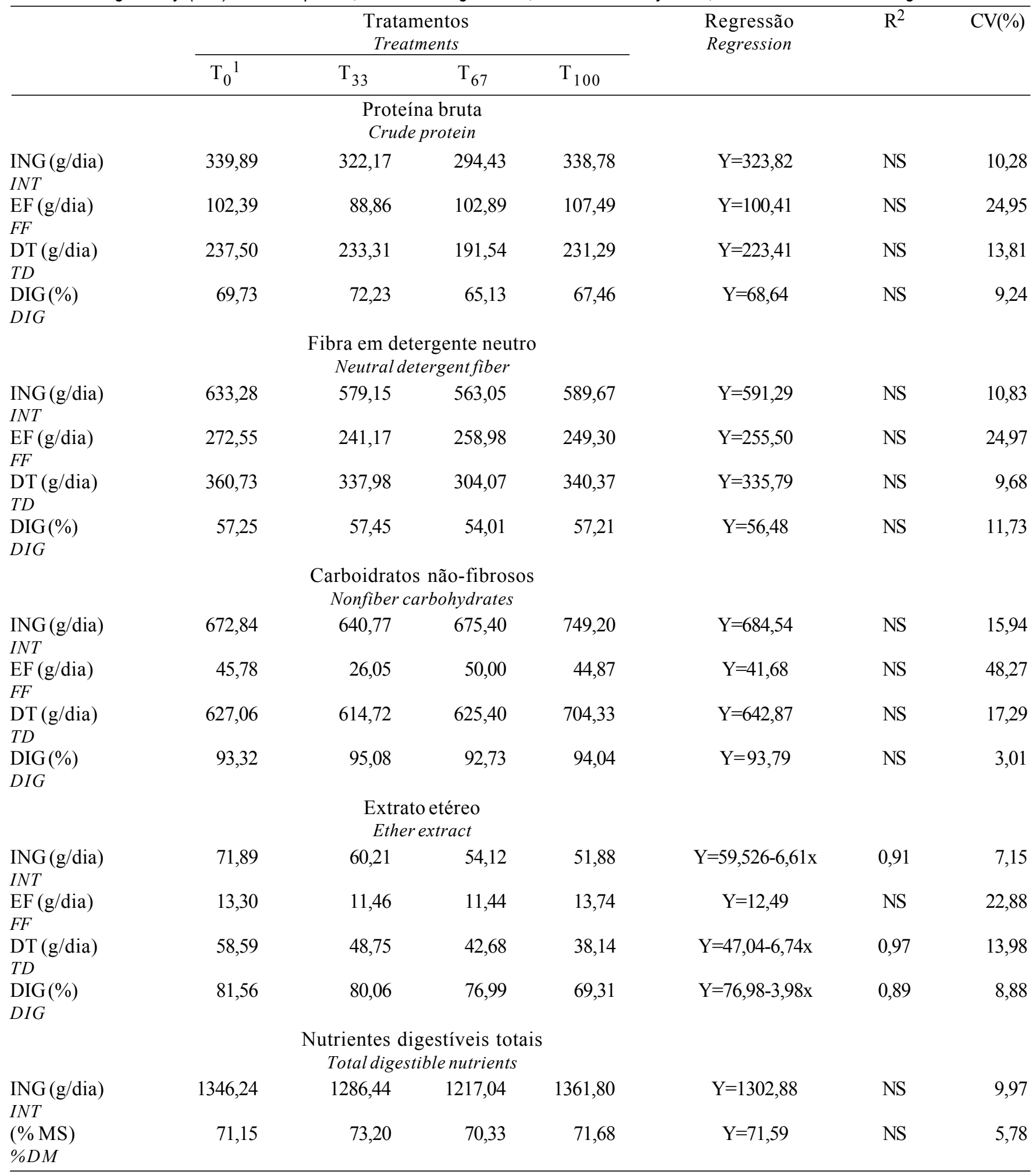

${ }^{1} \mathrm{~T}_{0}$ : dieta com $0 \%$ de substituição do milho pela farinha de varredura; $\mathrm{T}_{33}$ : dieta com $33 \%$ de substituição; $\mathrm{T}_{67}$ : dieta com $67 \%$ de substituição; $\mathrm{T}_{100}$ : dieta com $100 \%$ de substituição.

$T_{0}$ : diet with $0 \%$ replacement corn by cassava by-product meal; $T_{33}$ : diet with $33 \%$ replacement; $T_{67}$ : diet with $67 \%$ replacement; $T_{100}$ : diet with $100 \%$ replacement. 
valores de $\mathrm{pH}$ ruminal ou a condições desconhecidas que prejudicam a digestão da fibra.

Houve uma diminuição linear $(\mathrm{P}<0,05)$ da ingestão, bem como da digestão total e da digestibilidade total do extrato etéreo, com o aumento da inclusão dietética da farinha de mandioca de varredura.

O NDT não diferiu $(\mathrm{P}>0,05)$ entre as dietas estudadas, com média de $71,59 \%$, valor próximo ao estimado por dados das tabelas do NRC (1996), que foi de $73,69 \%$. A concentração energética das dietas indica o êxito obtido na substituição do milho, que é considerado uma fonte de energia padrão para a alimentação animal, pela farinha de mandioca de varredura, podendo ser incluída nas dietas de cabras leiteiras em lactação, em até $100 \%$ em substituição ao milho, sem prejuízo para a concentração energética das rações. Foi estabelecida a correlação entre a digestibilidade aparente da matéria orgânica (DIGMO) e o NDT, como pode ser observado na Figura 1.

As variáveis apresentaram correlação positiva entre si $(\mathrm{P}<0,05 ; \mathrm{r}=0,9472)$, permitindo estimativas do NDT a partir da equação NDT $(\%)=0,8897 \operatorname{DIGMO}(\%)+$ $10,9940\left(R^{2}=0,8972\right)$. Informação como esta pode ser muito interessante, já que o NDT é a forma de expressar a concentração energética dos alimentos mais utilizada pelos técnicos.

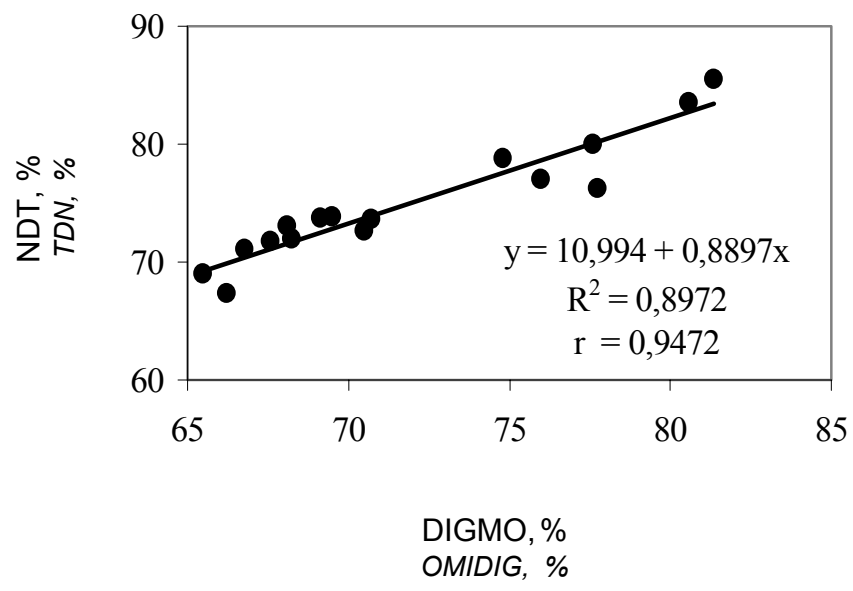

Figura 1 - Correlação entre a digestibilidade aparente da matéria orgânica (DIGMO) e nutrientes digestíveis totais (NDT).

Figure 1 - Corretation between apparent organic matter digestibility (OMDIG) and total digestible nutrients (TDN).
Os dados de produção de leite $(\mathrm{kg} / \mathrm{dia})$ e sua composição em relação ao extrato seco (\%) e à proteína bruta (\%) encontram-se na Tabela 4.

A produção média de leite foi de $2,1 \mathrm{~kg} / \mathrm{dia}$, com ingestão de MS de 1,8 kg/dia e 4,59 Mcal de energia metabolizável (EM)/dia, confirmando as estimativas de exigências pelo AFRC (1993) que, para cabras Saanen em lactação por volta de 3 meses de lactação, seriam necessários 1,8 kg de MS e 4,54 Mcal de EM/ dia para produzir 2,0 $\mathrm{kg}$ de leite /dia.

A substituição do milho pela farinha de mandioca de varredura não influenciou $(\mathrm{P}>0,05)$ a produção de leite, bem como a sua composição. Estes resultados confirmam outros obtidos por Khorasani et al. (1994) e Casper et al. (1999) e permitem utilizar a farinha de mandioca de varredura em dietas de cabras leiteiras, em substituição total ao milho, sem prejuízo na produção do leite e em sua composição quanto à porcentagem de extrato seco e proteína bruta.

Estudos de desempenho com ruminantes em lactação não evidenciam claramente que alimentos com baixas taxas de degradação ruminal do amido aumentem a produção de leite e proporcionem modificações em sua composição (Nocek \& Tamminga, 1991).

Maior produção de leite foi verificada em vacas leiteiras, quando foram alimentadas com fontes de amido com lenta (milho) degradação ruminal do amido, em comparação com fontes de rápida (cevada) degradação (McCarthy et al., 1989, Weiss et al., 1989). Os autores justificam esta maior produção devido à maior quantidade de ácidos graxos voláteis, formados durante a fermentação ruminal destas fontes. Outro aspecto importante a ser considerado é que a glicose absorvida no intestino delgado é utilizada com maior eficiência pelo metabolismo do ruminante para a produção de leite que os AGVs produzidos durante a fermentação ruminal e a disponibilidade de energia possui direta relação com a produção de leite (Nocek \& Tamminga, 1991).

A farinha de mandioca de varredura é um subproduto regional onde se localizam fecularias e farinheiras e cerca de 3 a $5 \%$ da mandioca industrializada é eliminada na forma de farinha de varredura e, em decorrência do custo baixo relativo às outras fontes energéticas e dos resultados obtidos neste trabalho e em outros realizados anteriormente (Caldas Neto, 1999; Marques, 1999; Fregadolli, 2000; Jorge et al., 2000; Zeoula et al., 2000), este alimento possui grande potencial a ser explorado na alimentação animal. 
Tabela 4 - Média, equações de regressão e coeficientes de determinação $\left(R^{2}\right)$ para a produção de leite $(P L)$ e sua composição em extrato seco (ES) e proteína bruta (PB)

Tabela 4 - Averages, regression equations and coefficients of determination $\left(R^{2}\right)$ for milk production $(M P)$ and its composition as dry extract $(D E)$ and crude protein $(C P)$

\begin{tabular}{|c|c|c|c|c|c|c|c|}
\hline & \multicolumn{4}{|c|}{$\begin{array}{c}\text { Tratamentos } \\
\text { Treatments }\end{array}$} & \multirow[t]{2}{*}{$\begin{array}{l}\text { Regressão } \\
\text { Regression }\end{array}$} & \multirow[t]{2}{*}{$\mathrm{R}^{2}$} & \multirow[t]{2}{*}{$\mathrm{CV}(\%)$} \\
\hline & $\mathrm{T}_{0}{ }^{1}$ & $\mathrm{~T}_{33}$ & $\mathrm{~T}_{67}$ & $\mathrm{~T}_{100}$ & & & \\
\hline & \multicolumn{4}{|c|}{$\begin{array}{l}\text { Proteína bruta } \\
\text { Crude protein }\end{array}$} & & & \\
\hline $\begin{array}{l}\mathrm{PL}(\mathrm{kg} / \mathrm{dia}) \\
M P(\mathrm{~kg} / d)\end{array}$ & 2,141 & 2,001 & 2,058 & 2,212 & $\mathrm{Y}=2,103$ & NS & 11,87 \\
\hline $\begin{array}{l}\mathrm{ES}(\%) \\
D E\end{array}$ & 11,30 & 11,00 & 11,34 & 11,23 & $\mathrm{Y}=11,22$ & NS & 3,71 \\
\hline $\begin{array}{l}\mathrm{PB}(\%) \\
C P\end{array}$ & 3,00 & 3,09 & 2,95 & 2,95 & $\mathrm{Y}=2,95$ & NS & 2,86 \\
\hline
\end{tabular}

${ }^{1} \mathrm{~T}_{0}$ : dieta com $0 \%$ de substituição do milho pela farinha de varredura; $\mathrm{T}_{33}$ : dieta com $33 \%$ de substituição; $\mathrm{T}_{67}:$ dieta com $67 \%$ de substituição; $\mathrm{T}_{100}$ : dieta com $100 \%$ de substituição.

$T_{0}$ : diet with $0 \%$ replacement corn by cassava by-product meal; $T_{33}$ : diet with $33 \%$ replacement; $T_{67}$ : diet with $67 \%$ replacement; $T_{100}$ : diet with $100 \%$ replacement.

\section{Conclusões}

O milho pode ser totalmente substituído pela farinha de mandioca de varredura por não alterar a digestão, excreção e digestibilidade da MS, MO, PB, FDN e CNE.

O teor de NDT não variou com a substituição do milho pela farinha de mandioca. A produção e composição do leite não foram afetadas pelo uso da farinha de mandioca.

\section{Literatura Citada}

AGRICULTURAL AND FOOD RESEARCH COUNCIL AFRC. Energy and protein requirements of ruminants. Wallington: CAB International, 1993. 159p.

BARBANO, D.M.; CLARK, J.L.; DUNHAM, C.E. et al. Kjeldahl method for determination of total nitrogen content of milk: Collaborative study. Journal of Association of Analytical Chemistry, v.73, p.849-859, 1990.

CALDAS NETO, S.F. Digestibilidade parcial e total, parâmetros ruminais e degradabilidade de rações com mandioca e resíduos das farinheiras. Maringá: Universidade Estadual de Maringá, 1999. 66p. Dissertação (Mestrado em Zootecnia) - Universidade Estadual de Maringá, 1999.

CASPER, D.P.; MAIGA, H.A.; BROUK, M.J. et al. Synchronization of carbohydrate and protein sources on fermentation and passage rates in dairy cows. Journal of Dairy Science, v.82, p.1779-1790, 1999.

DePETERS, E.J.; TAYLOR, S.J. Effects of feeding corn or barley on composition of milk and diet digestibility. Journal of Dairy Science, v.68, p.2027-2032, 1985.

FREGADOLLI, F.L. Efeito da degradabilidade ruminal do amido e do nitrogênio da dieta sobre o metabolismo ruminal e a digestibilidade em bovinos. Maringá: Universidade Estadual de Maringá, 2000. 68p. Dissertação (Mestrado em Zootecnia) - Universidade Estadual de Maringá, 2000.
HUNTINGTON, G.B. Starch utilization by ruminants: from basics to the bunk. Journal of Animal Science, v.75, p.852$867,1997$.

JORGE, J.R.V.; ZEOULA, L.M.; PRADO, I.N. et al. Desempenho de bezerros Holandeses alimentados com níveis de farinha de varredura. In: REUNIÃO ANUAL DA SOCIEDADE BRASILEIRA DE ZOOTECNIA, 37., 2000, Viçosa. Anais... Viçosa, MG: Sociedade Brasileira de Zootecnia, 2000.

JURJANZ, S.; COLIN-SCHOELLEN, O.; GARDEUR, J. N. et al. Alteration of milk fat by variation in the source and amount of starch in total mixed diet fed to dairy cows. Journal of Dairy Science, v.81, p.2924-2933, 1998.

KHORASANI, G.R.; DE BOER G.; ROBINSON, B. et al. Influence of dietary protein and starch on production and metabolic responses of dairy cows. Journal of Dairy Science, v.77, p.813-824, 1994.

MARQUES, J. Avaliação da mandioca e seus resíduos agroindustriais em substituição do milho na terminação de novilhas: desempenho e digestibilidade aparente in vivo. Maringá: Universidade Estadual de Maringá, 1999. 42p. Dissertação (Mestrado em Zootecnia) - Universidade Estadual de Maringá, 1999.

McCARTHY, R.D.; KLUZMEYER, Jr., T.H.; CLARK, J.H. et al. Effects of source of protein and carbohydrate on ruminal fermentation and passage of nutrients to the small intestine of lactating cows. Journal of Dairy Science, v.72, p.20022016, 1989.

NATIONAL RESEARCH COUNCIL - NRC. Nutrient requirement of beef cattle. 7 .ed. Washington, D.C.: National Academic Press, 1996. 242p.

NOCEK, J.E.; TAMMINGA, S. Site of digestion of starch in the gastrointestinal tract of dairy cows and its effect on milk yield and composition. Journal of Dairy Science, v.74, p.3598-3629, 1991.

OVERTON, T.R.; CAMERON, M.R.; ELLIOTT, J.H. et al. Ruminal fermentation and passage of nutrients to the duodenum of lactating cows fed mixtures of corn and barley. Journal of Dairy Science, v.78, p.1981-1991, 1995.

PEREIRA, J.R., ROSSI Jr., P. Manual prático de avaliação nutricional de alimentos. Piracicaba: Fundação de Estudos Agrários "Luiz de Queiroz", 1995. 25p. 
PHILIPPEAU, C.; MARTIN, C.; MICHALET-DOREAU, B. Influence of grain source on ruminal characteristics and rate, site, and extent of digestion in beef steers. Journal Animal Science, v.77, p.1587-1596, 1999.

RODE, L.M.; SATTER, L.D. Effect of amount and length of alfafa hay in diets containing barley or corn on site of digestion and rumen microbial protein synthesis in dairy cows. Canadian Journal of Animal Science, v.68, p.445454, 1988.

UNIVERSIDADE FEDERAL DE VIÇOSA - UFV. SAEG Sistema para análise estatística e genética. Viçosa, $\mathrm{MG}$ : 1983. 68p.

SCHIMIDELY, P.; LLORET-PUJOL, M.; BAS, P. et al. Influence of feed intake and source of dietary carbohydrate on milk yield and composition, nitrogen balance, and plasma constituents of lactating goats. Journal of Dairy Science, v.82, p.747-755, 1999.

SILVA, D.J. Análises de alimentos. 2.ed. Viçosa: Universidade Federal de Viçosa, 1990. 166p.

Van SOEST, P.J.; ROBERTSON, J. B.; LEWIS, B.A. Symposium: Methods for dietary fiber, neutral detergent fiber, and nonstarch polysaccharides in relation to animal nutrition. Journal of Dairy Science, v.74, p.3583-3597, 1991.

WEISS, W. Energy prediction equations for ruminant feeds. In: CORNELL NUTRITION CONFERENCE FOR FEED MANUFACTURERS, 61., 1999, Ithaca. Proceedings... Ithaca: Cornell University, 1999. p.176-185.
WEISS, W.P.; FISHER, G.R.; ERICKSON, G.M. Effect of source of neutral detergent fiber and starch on nutrient utilization by dairy cows. Journal of Dairy Science, v.72, p.2308-2315, 1989.

WILLIANS, C.H., DAVID, D.J., ILSMAA, O. The determination chromic oxide in faeces samples by atomic absorption spectrophotometry. Journal of Animal Science, v.359, p.391, 1962.

ZEOULA, L.M.; PRADO, I.N.; CALDAS NETO, S.F. et al. Substituição do milho pela farinha de varredura (Manihot sculenta) sobre o consumo voluntário e digestibilidade em ovinos. In: REUNIÃO ANUAL DA SOCIEDADE BRASILEIRA DE ZOOTECNIA, 37., 2000, Viçosa. Anais... Viçosa, MG: Sociedade Brasileira de Zootecnia, 2000.

Recebido em: 24/05/01

Aceito em: 05/11/01 